\title{
Evaluation of Children with Nephrotic Syndrome: A Single- Center Experience
}

\author{
Cem Alatas ${ }^{1}$ (D) Yilmaz Tabel²* (D), Ahmet Taner Elmas² (D), and Senay Zirhli Selcuk ${ }^{2}$ (D) \\ ${ }^{1}$ Faculty of Medicine, Department of Pediatrics, Inönü University, Malatya, Turkey \\ ${ }^{2}$ Faculty of Medicine, Department of Pediatric Nephrology, Inönü University Malatya, Turkey
}

\begin{abstract}
Objective: Nephrotic syndrome (NS) is one of the most frequent occurring chronic kidney diseases in children. In this study, our aim was to assess the sociodemographic structure, determination of clinical data, diagnostic approaches, treatment methods applied and the factors effective on prognosis in patients followed with a diagnosis of nephrotic syndrome in our clinic.
\end{abstract}

Method: The files of 256 patients diagnosed with primary nephrotic syndrome between the ages of 0 and 18 who were followed in Department of Pediatric Nephrology during a period of 15 years between 2004 and 2019 were examined retrospectively. 220 patients whose data were sufficient and who had a sufficient follow-up time were included in the study.

Results: 137 of our patients were male, 83 were female and the ratio of male/female was 1.65. Average onset age of the cases was $4.8 \pm 2.6$ years ( 1 months-16 years). Renal disease history in the family was $16.4 \%$ and the rate of consanguineous marriage was $25.9 \%$. $24 \%$ of our patients were found to have microscopic hematuria, $28.2 \%$ were found to have hypertension. Of the patients who received biopsy, 32 were determined as FSGS, 18 as MCD, 11 as MPGN, 3 as IgM nephropathy, 2 as hereditary nephrite, 2 as MezPGN, 1 as MGN, 1 as congenital NS and 2 as other reasons. While a total of 193 patients $(87.7 \%)$ were sensitive to steroid, 27 patients $(12.2 \%)$ were found to be resistant to steroid. While $78(35.5 \%)$ of the patients were followed with no relapse, 120 (54.5\%) patients were relapsing and $22(10 \%)$ patients had frequent relapses. In their follow-up, mortality rate of our patients was found as $2.7 \%$.

Conclusion: With this study, we assessed children with primary nephrotic syndrome in our area comprehensively for the first time. Consanguineous marriage rate was higher in our patients. Our findings were also remarkable in terms of demonstrating that primary NS follows its own course in each child depending on the underlying genetic structure.

\section{Keywords}

Children, Nephrotic syndrome, Treatment, Course

\section{Introduction}

Nephrotic syndrome (NS) is a kidney disorder characterized by diffuse edema, severe proteinuria, low albumin, and hyperlipidemia. The most important sign of nephrotic syndrome is proteinuria. Massive proteinuria in children is defined as $>40 \mathrm{mg} / \mathrm{m}^{2} /$ hour protein excretion in urine or a protein/creatinine $(\mathrm{mg} / \mathrm{mg}$ ) ratio above 2 in the first urine of the morning. Hypoalbuminemia is the plasma albumin level of 2.5 $\mathrm{g} / \mathrm{dl}$ and lower. In the lack of any comorbid systemic disease, it is called primary idiopathic nephrotic syndrome (90\%), otherwise, it is termed as a secondary nephrotic syndrome [1]. Although the prevalence of nephrotic syndrome varies according to race, age, and geographic region, its incidence is reported as 1.99-4.71 per 100.000 children in a year [2]. The cumulative prevalence is 16 per 100.000 cases [3]. This disease has a twofold greater incidence in boys than in girls
[1-3]. One of the most commonly observed primary nephrotic syndromes is minimal change disease (MCD). The minimal change disease presents any signs in light microscopy and immune fluorescence; however, it is recognized by flattening in the podocytes' thread-like protrusions in electron microscopy. It responds to steroid therapy with an $80 \%$ rate. The

*Corresponding author: Yilmaz Tabel, Faculty of Medicine, Department of Pediatric Nephrology, İnönü Universitesi, Turgut Özal Tıp Merkezi, Pediatrik Nefroloji BD 44280, Malatya, Turkey, Tel: +90-422-341-06-60-(5311), Fax: +90-422-341-07-28

Accepted: October 28, 2020

Published online: October 30, 2020

Citation: Alatas C, Tabel Y, Elmas AT, et al. (2020) Evaluation of Children with Nephrotic Syndrome: A Single-Center Experience. Ann Nephrol 5(1):78-83 
second commonly observed glomerular disease that causes primary nephrotic syndrome in children following MCD is focal segmental glomerulosclerosis (FSGS). Focal segmental glomerulosclerosis is the most commonly seen glomerular disease that causes chronic renal failure in children. Approximately $30 \%$ of patients progressed to end-stage renal failure in the following five years [4]. Patients with nephrotic syndrome may clinically have edema, oliguria, anorexia, gastrointestinal disorders, and hepatomegaly. The most frequent complications are the susceptibility to infection, thromboembolism, growth retardation, and osteoporosis [5].

Although specific treatments in nephrotic syndrome could vary depending on the primary disease, the general treatment principles are alike. The corticosteroids are frequently used in first treatment. The side effects such as drug-related susceptibility to infection, thromboembolism, growth retardation, osteoporosis, and obesity could be observed [6]. The incidence of diseases that cause nephrotic syndrome and also, their prognosis may differ according to the area of residency. In our region, there is no comprehensive study including data on diagnosis, treatment, and follow-up of patients with nephrotic syndrome.

In this study, we aimed to identify sociodemographic characteristics, clinical data and diagnostic approaches to evaluate the effect of treatment methods on prognosis in a group of patients followed-up with a diagnosis of nephrotic syndrome in our clinic.

\section{Patients and Methods}

The files of 256 patients diagnosed with primary nephrotic syndrome between the ages of 0-18, who were followed up in the Department of Pediatric Nephrology, University of İnönü in Malatya located in eastern Anatolia in Turkey, 15-year period from 2004 to 2019 was analyzed retrospectively. A total of 220 patients with complete data and a sufficient follow-up period were enrolled in the study.

In our study, data collection and assessment processes were carried out between March 2018 and March 2019. The ethical approval for our study was obtained from the local ethics committee on March 27, 2018 (Ethics Committee Decision No: 2018/7-18).

The data obtained by examining the files of the patients were recorded into pre-prepared forms. Firstly, demographic data such as name, surname, birth date, place of birth, and city where he/she comes for attending to the clinic, age of diagnosis, parental consanguinity, and family history of NS or the presence of any other kidney disorders were registered. Afterward, the history of infection, parasitosis, allergy, or atopy at the time of admission, the presence of any comorbid disease, any pathological symptoms during the physical examination, and blood pressure values, and the diffuseness of edema at the time of admission were recorded.

Patients who had proteinuria at the nephrotic level (40 $\mathrm{mg} / \mathrm{m}^{2} /$ hour in urine or spot urine protein/creatinine $(\mathrm{mg} /$ $\mathrm{mg}$ ) ratio greater than 2$)$, hypoalbuminemia $(<2.5 \mathrm{~g} / \mathrm{dl})$, diffuse edema, and hyperlipidemia (cholesterol $>200 \mathrm{mg} / \mathrm{dl}$ or triglyceride $>170 \mathrm{mg} / \mathrm{dl}$ ) were assessed as NS. In two of three urine samples collected for urine analysis, the presence of erythrocyte more than 5 in $40 \%$ enlarged field of urine sediment was accepted as microscopic hematuria and the presence of visible discoloration was called as macroscopic hematuria. The blood pressure of the patients at the time of admission was measured. $95^{\text {th }}$ percentile systolic and diastolic blood pressure values matching with the height percentiles of the patients were identified, and the values higher than this were accepted as hypertension [7]. Spot urine protein/ creatinine $(\mathrm{mg} / \mathrm{mg}$ ) ratio was used for diagnosis in these patients since some patients could not collect for 24-hour urine due to being younger. The values below 0.2 were accepted as normal, while the values above 2 were identified as nephrotic proteinuria. 24 hour-urine samples of patients who could collect were examined. The protein excretion amount below $4 \mathrm{mg} / \mathrm{m}^{2} /$ hour was accepted as normal, while values above $40 \mathrm{mg} / \mathrm{m}^{2} /$ hour were considered as proteinuria at the nephrotic level.

The patients were divided into two groups, namely the primary diagnoses like MCD, FSGS, mesangial proliferative glomerulonephritis (MesGN), membranoproliferative GN (MPGN), membranous nephropathy (MN), congenital NS, immunoglobulin $\mathrm{M}$ (IgM) nephropathy, hereditary nephritis, and other diagnoses. Of these patients, 72 patients with biopsy indication (patients whose age $<1$ year, age $>10$ years, who had low C3 and/or C4, steroid unresponsiveness, a sign of systemic disease, macroscopic hematuria, and low GFR) had undergone a biopsy. The histopathological diagnoses were grouped according to the examination of obtained materials through electron microscopy and immunofluorescence examinations.

As the first treatment for all patients, the drug protocol was arranged as following; $60 \mathrm{mg} / \mathrm{m}^{2} /$ day $(2 \mathrm{mg} / \mathrm{kg} /$ day) prednisolone was started in a single dose in the morning and medication was continued as such for four or six weeks, then a single dose of $40 \mathrm{mg} / \mathrm{m}^{2} /$ every other day (eight weeks) was given, and finally, the steroid was discontinued. Significant decrease in proteinuria $\left(<4 \mathrm{mg} / \mathrm{m}^{2} /\right.$ hour or negative with dipstick for three consecutive days), spot urine protein/creatinine $(\mathrm{mg} / \mathrm{mg}$ ) ratio less than 0.2 , and albumin returning to normal levels $(3.5 \mathrm{~g} / \mathrm{dl})$ considered as remission. Recurrence of severe proteinuria ( $>40 \mathrm{mg} / \mathrm{m}^{2} /$ hour or urine albumin $\geq$ +2 in dipsticks in three consecutive days) and usually the coexistence of edema were accepted as relapse in the patient who was already in remission. The patients having four or more episodes of nephrotic syndrome in a 12-months period was considered as frequently relapsing nephrotic syndrome. The patients who were in remission after responding to steroid therapy alone were defined as a steroid-responsive or steroid-sensitive nephrotic syndrome. Likewise, the patients without any remission despite prednisolone treatment of 60 $\mathrm{mg} / \mathrm{m}^{2} /$ day ( $2 \mathrm{mg} / \mathrm{kg} /$ day) for four weeks or the patients who did not go into remission despite $60 \mathrm{mg} / \mathrm{m}^{2} /$ day $(2 \mathrm{mg} / \mathrm{kg} /$ day) prednisolone treatment for six weeks and subsequently, 3-6 times intravenous pulse methylprednisolone $(30 \mathrm{mg} / \mathrm{kg}$ ) treatment every other day was defined as having steroid-resistant nephrotic syndrome. The patients in whom proteinuria disappeared by steroid treatment, but relapsed within 
the following 2 weeks, after steroid was reduced or discontinued were defined as having steroid-dependent nephrotic syndrome, and the patients were grouped according to these definitions.

All of our patients received steroid treatment. Drugs initiated in patients who relapsed or had steroid resistance after receiving steroid treatment were also grouped as cyclophosphamide, cyclosporine, tacrolimus, levamisole, mycophenolate mofetil (MMF) and other immunosuppressive drugs, and their combinations.

\section{Statistical Analysis}

The analysis was carried out by the IBM SPSS statistics 22.0 program. Data were presented as mean \pm standard deviation, median (min-max), numbers, and percentages. The compliance of the data with a normality assumption was tested with the Kolmogorov-Smirnov test, and the Mann Whitney $\mathrm{U}$ test was used in the analysis of continuous variables that did not demonstrate normal distribution. Fisher's Exact, Yates corrected Chi-square and Pearson Chi-square tests were used in the analysis of categorical variables, and the results where p-value was $<0.05$ were considered as statistically significant.

\section{Results}

Out of 220 patients between the ages of 0 to 18 who participated in the study, 137 were boys (62.3\%) and 83 were girls (37.7\%). The average onset age at the time of diagnosis was $4.8 \pm 2.6$ years (lower-upper limit: 0.1-16 years) and male/female ratio was 1.65 . There were 36 patients $(16.4 \%)$ with a family history of kidney disorder, while 11 patients (5\%) had a family history of nephrotic syndrome. Parental consanguinity was found $25.9 \%$ in our patients.

Table 1: The baseline demographic and clinical features of the patients.

\begin{tabular}{|l|l|l|}
\hline Patient Characteristic & n & \% \\
\hline Sociodemographic & $137 / 83$ & $62.3 / 37.7$ \\
\hline Boy/Girl & 57 & 25.7 \\
\hline Consanguineous marriage & 36 & 16.4 \\
\hline Kidney disease in family & 11 & 5 \\
\hline Nephrotic syndrome in family & & \\
\hline Clinical & & $5 / 25.4$ \\
\hline Macroscopic/microscopic hematuria & $11 / 54$ & 28.2 \\
\hline Hypertension & 62 & \\
\hline
\end{tabular}

Microscopic hematuria is not an expected symptom in nephrotic syndrome, especially in $\mathrm{MCD}$, which is very common in our children. Total 11 of our patients $(5 \%)$ had macroscopic hematuria, while microscopic hematuria was detected in 54 patients (24.5\%). Hypertension was present in 62 (28.2\%) of our patients at the time of diagnosis. The demographic and clinical features of patients showed that (Table 1).

Renal biopsy was carried out in 72 of our patients who were under follow-up. According to the pathology results of our patients who had undergone a biopsy; 32 patients evaluated as FSGS, 18 patients as MCD, 11 patients as MPGN, 3 patients as IgM nephropathy, 2 patients as hereditary nephritis, 2 patients as other causes, 2 patients as MesGN, one patient as $\mathrm{MN}$, and one patient was assessed as congenital NS.

According to the patients' response to steroid therapy, they are divided into three categories namely steroid-sensitive, steroid-resistance, and steroid-dependent. 193 of our patients had a steroid-response, while 27 patients had a steroid-resistance. In the follow-up of the patients with steroid-response, 46 patients were identified as steroid-dependent. We compared the response of the patients to the steroid treatment with gender, family history of NS, familial kidney disease, parental consanguinity, macroscopic hematuria, microscopic hematuria, and hypertension (Table 2).

A statistically significant difference was identified $(p<$ 0.001 ) when we compared the pathological finding of the patients with steroid response (Table 3).

The cases were grouped according to their relapse status; 78 patients $(35.5 \%)$ were followed up without reporting any relapse, 120 patients (54.5\%) had at least one relapse and 22

Table 2: A comparison of demographic and clinical features of steroid-sensitive and steroid-resistant patients.

\begin{tabular}{|l|l|l|l|}
\hline & $\begin{array}{l}\text { SSNS } \\
\text { (n:193) }\end{array}$ & $\begin{array}{l}\text { SRNS } \\
\text { (n:27) }\end{array}$ & $\mathbf{p}$ \\
\hline Gender (Boy/Girl) & $125 / 68$ & $12 / 15$ & 0.052 \\
\hline Nephrotic syndrome in family & 8 & 3 & 0.22 \\
\hline Kidney disorder in family & 29 & 7 & 0.25 \\
\hline Parental consanguinity & 47 & 10 & 0.061 \\
\hline Macroscopic hematuria & 8 & 3 & $\mathbf{0 . 0 2}$ \\
\hline Hypertension & 53 & 9 & 0.12 \\
\hline
\end{tabular}

SSNS: Steroid-sensitive nephrotic syndrome; SRNS: Steroid- resistant nephrotic syndrome.

Table 3: A comparison of pathological finding and steroid-response.

\begin{tabular}{|l|l|l|l|l|l|l|l|l|l|l|l|}
\hline & MCD & FSGS & MesGN & MPGN & MN & Congenital NS & $\begin{array}{l}\text { IgM } \\
\text { nephropathy }\end{array}$ & $\begin{array}{l}\text { Hereditary } \\
\text { nephritis }\end{array}$ & Other & Total & $\mathbf{p}$ \\
\hline SSNS & 149 & 22 & 2 & 11 & 1 & 0 & 3 & 2 & 3 & 193 & $<0.001$ \\
\hline SRNS & 8 & 13 & 0 & 0 & 0 & 5 & 1 & 0 & 0 & 27 & $<0.001$ \\
\hline Total & $\mathbf{1 5 7}$ & $\mathbf{3 5}$ & $\mathbf{2}$ & $\mathbf{1 1}$ & $\mathbf{1}$ & $\mathbf{5}$ & $\mathbf{4}$ & $\mathbf{2}$ & $\mathbf{3}$ & $\mathbf{2 2 0}$ & \\
\hline
\end{tabular}

SSNS: Steroid-sensitive nephrotic syndrome; SRNS: Steroid-resistant nephrotic syndrome; MCD: Minimal change disease; FSGS: Focal segmental glomerulosclerosis; MesGN: Mesangial proliferative glomerulonephritis; MPGN: Membranoproliferative glomerulonephritis; MN: Membranous nephropathy. 
Citation: Alatas C, Tabel Y, Elmas AT, et al. (2020) Evaluation of Children with Nephrotic Syndrome: A Single-Center Experience. Ann Nephrol 5(1):78-83

Table 4: The relationship of primary diagnosis and relapse.

\begin{tabular}{|l|l|l|l|l|l|l|l|l|l|l|}
\hline & MCD & FSGS & MesGN & MPGN & MN & $\begin{array}{l}\text { Congenital } \\
\text { NS }\end{array}$ & $\begin{array}{l}\text { IgM } \\
\text { nephropathy }\end{array}$ & $\begin{array}{l}\text { Hereditary } \\
\text { nephritis }\end{array}$ & Other & $\mathbf{p}$ \\
\hline No-relapse & 68 & 1 & 2 & 4 & 0 & 0 & 1 & 0 & 2 & $<0.05$ \\
\hline Relapsing & 83 & 22 & 0 & 7 & 1 & 3 & 2 & 2 & 0 \\
\hline $\begin{array}{l}\text { Frequent } \\
\text { relapse }\end{array}$ & 6 & 12 & 0 & 0 & 0 & 2 & 1 & 0 & 1 \\
\hline
\end{tabular}

MCD: Minimal change disease; FSGS: Focal segmental glomerulosclerosis; MesGN: Mesangial proliferative glomerulonephritis; MPGN: Membranoproliferative glomerulonephritis; MN: Membranous nephropathy.

patients (10\%) were accepted as having frequent relapses. After comparing patients' primary diagnosis and their relapse status, there was a statistically significant difference between primary diagnosis and follow-up without having any relapse and frequent relapses, while no statistically significant difference was identified between primary diagnosis and relapsing (Table 4).

After we compared the treatment that the patients received according to their relapse status, a significant relationship was determined between receiving steroid treatment, follow-up without any relapse, relapsing, and frequent relapses. There was a significant relationship between receiving cyclophosphamide, cyclosporine, levamisole, and follow-up without any relapse and relapsing, but any significant relationship could be detected for frequent relapses.

\section{Discussion}

We assessed children with primary nephrotic syndrome in our area comprehensively for the first time. In this study, our findings were evaluated according to demographic and clinic characteristics, response to treatment, prognosis and compared with national data and literature.

In our study, the male/female ratio was 1.64 and the average age at the time of diagnosis was 4.8 years. In our study, the male gender ratio was prominently higher, similar to the studies conducted in our country and different regions of the world [8-10]. The average age for onset was 6/5.2 years in studies conducted in Samsun and Trabzon, it was determined as 3.9/3 years in studies conducted in Konya and Ankara [1113].

The frequency of consanguineous marriages in our country according to the Turkey Statistical Institute data was found to be $23.3 \%$. In Turkey, the frequency of consanguineous marriage in patients with nephrotic syndrome was identified as $18.3 \%$ in the study conducted in İstanbul by Ovunc, et al. [12] and as $15.2 \%$ in a study carried out by Atilla, et al. in Samsun [13], while the frequency was determined as $25.9 \%$ in our study. The higher rate of consanguineous marriage in our study compared to the other two studies can be explained by the higher frequency of consanguineous marriage in Eastern and Southeastern Anatolia regions where our patients had been referred from.

The presence of hypertension and steroid resistance are signs that should attract our attention for taking into account of histopathological diagnosis other than MCD. Therefore, it is important to detect hypertension after the physical examination. Hypertension was present in $28.2 \%$ of our patients at the time of diagnosis. This rate was found to be similar to the studies of Ovunc, et al. and Gheissari, et al. [12-14]. In our study, the rate of relapse frequency, steroid resistance, and progression to end-stage renal disease in patients with hypertension were considerably higher than patients without hypertension. According to these results, the presence of hypertension can be considered as a poor prognostic factor in nephrotic syndrome.

In steroid-sensitive nephrotic syndrome, although transient microscopic hematuria was observed in $15-20 \%$ of patients, this rate was higher in steroid-resistance patients. Macroscopic hematuria is generally not an expected sign and is mostly seen in glomerulonephritis patients [15]. In our study, microscopic hematuria was detected in $24.5 \%$ of patients. This rate was reported as $27 \%$ in the study of Constantinescu, et al. [16].

Mortazavi and Khiavi reported a higher incidence of hematuria in girls than in boys in their study [9]. Hematuria was more common in girls among our patients. Studies have demonstrated that hematuria in patients with NS increases the frequency of steroid-resistance in the treatment [9-14]. In our study, microscopic hematuria was observed in a total of 54 patients, while 13 of them were evaluated as SRNS. This result was found to be compatible with other studies.

Renal biopsy was performed in 72 patients (32\%) who met the biopsy indication criteria. In different studies, the indication rate for renal biopsy has been reported to be 7-42\% [1719]. Histopathological diagnosis of our patients was identified as following; 44.4\% FSGS, 25\% MCD, 15.2\% MPGN, 4.2\% IgM nephropathy, 2.8\% MesGN, 2.8\% hereditary nephritis, $1.4 \%$ $\mathrm{MN}, 1.4 \%$ congenital NS, and $2.8 \%$ other reasons. In the examination of the studies conducted in Turkey about this subject, the most common histopathological diagnosis in children who had undergone a biopsy for similar indications were FSGS and MPGN $[11,13,20]$, while in studies conducted in the world, the diagnoses of FSGS and MCD were detected with a rate, similar to our results $[21,22]$. In the study of Ronald Hogg, et al. investigating children with NS in years between 1985 and 2002, they identified that the incidence of FSGS increased significantly (from $0.37 / 100.000$ to $0.94 / 100.000$ ) [23]. Many studies conducted in recent years have revealed that the prevalence of FSGS increases every year [23-25]. Consequently, FSGS should be considered primarily as a histopathological diagnosis in patients who do not have clinical 
features of MCD or have a steroid-resistant NS. Therefore, we consider that biopsy should be carried out in patients with an onset age of $<1$ or $>10$ years, who have a lack of response to a steroid, have low complement levels, have signs of systemic involvement, macroscopic hematuria, and persistent hypertension.

Steroid response is the main factor determining how the prognosis will be during the follow-up of patients with nephrotic syndrome [5]. In the study of Safai, et al. [18] in Iran, the steroid- resistance was found to be $23.4 \%$, while in a study conducted by Bircan, et al. in Turkey between 1994 and 2000 this rate was detected as $13 \%$. In our study, while the steroid resistance was $12.2 \%, 46$ patients $(20.4 \%)$ were detected as steroid-dependent, in accordance with the literature. The frequency of steroid-resistance was found to be higher in female patients in the studies conducted in Iran and Arabia $[9,26]$, however, any significant differences were identified between gender and steroid-resistance in the study conducted by Kim, et al. in North America [27]. Furthermore, there was no significant difference between gender and steroid-resistance in our patients. In addition, we did not notice any significant relationship between steroid-resistance, and NS in the family, and parental consanguinity.

We compare the histopathological diagnosis of our patients with their steroid responses. It was identified that the histopathology of $49 \%$ steroid-resistant patients indicates the diagnosis of FSGS, while this rate was found to be $60 \%$ in the study of Büscher, et al. [28] and 50\% in the study of Ovunc, et al. [12]. There were no significant differences in nephrotic syndrome in family and parental consanguinity from SRNS group. This result is notable in terms of supporting the need for kidney biopsy in steroid-resistant patients.

The aim of the treatment in nephrotic syndrome is to enable the patient to go into remission as soon as possible, to prevent relapsing as much as possible, and to minimize the side effects of the treatments [5]. After initial treatment, most patients go into remission within the first month. No relapse is observed in $10-20 \%$ of the patients, while relapse occurs in $30 \%$ of the patients a few months later following cessation of the treatment. In the remaining $50 \%$ relapse occurs immediately after the cessation of steroid treatment or when the dose is reduced [29]. In our study, the follow-up rate without any relapsing was $35 \%$, while $10 \%$ of patients had frequent relapses and $54.5 \%$ had a history of relapse at any time. There was a significant relationship between the pathological diagnosis of our patients, follow-up without any relapse, and frequent relapses. These results were in consistent with other studies conducted in Turkey $[10,12]$. Pathological diagnosis can be predicted according to the relapse status of the patients after the first treatment. FSGS and congenital NS should be taken into account in patients with a history of frequent relapses, while MCD could be considered in patients who are followed up without any relapse.

In our study, steroid treatment was initiated in all our patients. All immunosuppressive drugs were added to the treatment according to the relapse status and steroid response. In one study, it was reported that the longer the first steroid treatment is given to the patient, the longer the remission period and the lower the frequency of relapse will be [30]. In our study, $52.3 \%$ of our patients used only steroids, $15 \%$ steroid + cyclophosphamide, $15 \%$ steroid + cyclosporine-A, $9.5 \%$ steroid + levamisole, and the remaining $12.4 \%$ received various combinations of these medications. Total 79 of 115 patients who received only steroids were followed-up without any relapse, while 37 patients experienced relapse in any period. In our clinic, the duration of the steroid treatment protocol in the first diagnosis as long as 5-6 months was considered as substantial in terms of preventing relapse and reducing the use of other drugs, as similar to the literature $[28,30]$.

In conclusion, after evaluating children with primary nephrotic syndrome in a sufficient period with this comprehensive and retrospective study, we identified that the demographic characteristics, clinical findings, and prognosis of our patients in our region were similar to those in the literature. These findings were also remarkable in terms of demonstrating that primary NS follows its own course in each child depending on the underlying genetic structure. We believe that multi-center studies should be conducted to reveal regional or national differences regarding the long term results of these findings.

\section{Conflicts of Interests}

We have nothing to declare.

\section{References}

1. Bagga A, Mantan M (2005) Nephrotic syndrome in children. Indian J Med Res 122: 13-28.

2. Banh TH, Hussain-Shamsy N, Patel V, et al. (2016) Ethnic Differences in Incidence and Outcomes of Childhood Nephrotic Syndrome. Clin J Am Soc Nephrol 11: 1760-1768.

3. Calışkan S (2008) Nephrotic syndrome. Türkiye Klinikleri J Pediatr Sci 4: 67-71.

4. Holt RCL, Webb JA (2002) Management of nephrotic syndrome in childhood. Current Pediatrics 12: 551-60.

5. Kher KK (2007) Nephrotic syndrome. In: Kher KK, Clinical Pediatric Nephrology. ( $2^{\text {nd }}$ edn), Informa Healthcare, Oxon, 155-194.

6. Eddy AA, Symons JM (2003) Nephrotic syndrome in childhood. Lancet 362: 629-639.

7. Rao G (2016) Diagnosis, Epidemiology, and Management of Hypertension in Children. Pediatrics 138: e20153616.

8. Srivastava T, Simon SD, Alon US (1999) High incidence of focal segmental glomerulosclerosis in nephrotic syndrome of childhood. Pediatr Nephrol 13: 13-18.

9. Mortazavi F, Khiavi YS (2011) Steroid response pattern and outcome of pediatric idiopathic nephrotic syndrome: A single-center experience in northwest Iran. Ther Clin Risk Manag 7: 167-171.

10. Bircan Z, Yılmaz A, Katar S, et al. (2002) Childhood idiopathic nephrotic syndrome in Turkey. Pediatr Int 44: 608-611.

11. Peru H, Karagöl C, Elmacı AM, Kara F (2008) Nefrotik Sendromlu 141 olgunun retrospektif analizi. Selçuk Tıp Dergisi 25: 23-30.

12. Hacıhamdioğlu Ö, et al. (2015) Nefrotik sendrom tanılı çocukların uzun dönem sonuçları Türk Ped Arş 50: 37-44. 
13. Van A, İşlek i, Dağdemir A, et al. (2001) Çocukluk Çağı Nefrotik Sendromu: 230 olgunun değerlendirilmesi. OMÜ Tıp Dergisi 18: 71-90.

14. Gheissari A, Attarzadeh $H$, Sharif $H$, et al. (2011) Steroid dependent and independent ocular findings in Iranian children with nephrotic syndrome. Int J Prev Med 2: 264-268.

15. Niaudet $P$, Olivia B (2009) Idiopathic nephrotic syndrome in children: Clinical aspects. In: Avner ED, Harmon WE, Niaudet $P$, Yoshikawa N, Pediatric Nephrology. Springer, Velag Berlin Heidelberg, 667-702.

16. Constantinescu AR, Shah HB, Foote Pharm EF, et al. (2000) Predicting first-year relapses in children with nephrotic syndrom. Pediatrics 105: 492-495.

17. Mekahli D, Liutkus A, Ranchin B, et al. (2009) Long-term outcome of idiopathic steroid resistant nephrotic syndrome: A multicenter study. Pediatr Nephrol 24: 1525-1532.

18. Safaei A, Maleknejad S (2009) Spectrum of childhood nephrotic syndrome in Iran: A single center study. Indian J Nephrol 19: $87-$ 90.

19. Chang JW, Tsai HL, Wang HH, et al. (2009) Clinicopathological features and prognosis of Chinese children with idiopathic nephrotic syndrome between different age groups. Eur J Pediatr 168: 1189-1194.

20. Yavaşcan Ö, Aksu N, Erdoğan H, et al. (2005) Çocuklarda böbrek biyopsi sonuçlarının değerlendirilmesi: On bir yıllık süre. Türk Nefroloji Diyaliz ve Transplantasyon Dergisi 14: 195-201.

21. Ejaz I, Khan HI, Javaid BK, et al. (2004) Histopathological diagnosis and outcome of paediatric nephrotic syndrome. J Coll Physicians Surg Pak 14: 229-233.
22. Abeyagunawardena AS, Trompeter RS (2008) Increasing the dose of prednisolone during viral infections reduces the risk of relapse in nephrotic syndrome: a randomised controlled trial. Arch Dis Child 93: 226-228.

23. Hogg R, Middleton J, Vehaskari VM (2007) Focal segmental glomerulosclerosis-epidemiology aspects in children and adults. Pediatr Nephrol 22: 183-186.

24. Batinic $D$, Miloševic $D$, Coric $M$, et al. (2012) Idiopathic nephrotic syndrome in children: Review of 282 Croatian cases. Clin Nephrol 78: 116-121.

25. Korbet SM (2012) Treatment of primary focal segmental glomerulosclerosis. Kidney Int 62: 2301-2310.

26. Kari JA, Halawani M, Mokhtar G, et al. (2009) Pattern of steroid resistant nephrotic syndrome in children living in the Kingdom of Saudi Arabia: A single center study. Saudi J Kidney Dis Transpl 20: 854-857.

27. Kim SJ, Bellew CA, Silverstein DM, et al. (2005) High incidence of initial and late steroid resistance in childhood nephrotic syndrome. Kidney Int 68: 1275-1281.

28. Büscher AK, Kranz B, Büscher R, et al. (2010) Immunosuppression and renal outcome in congenital and pediatric steroid- resistant nephrotic syndrome. Clin J Am Soc Nephrol 5: 2075-2084.

29. Hodson EM, Willis NS, Craig JC (2007) Corticosteroid therapy for nephrotic syndrome in children. Cochrane Database Syst Rev: CD 001533.

30. Hodson EM, Knight JF, Willis NS, et al. (2005) Corticosteroid therapy for nephrotic syndrome in children. Cochrane Database Syst Rev: CD001533. 